\title{
CLINICO-PATHOLOGICAL CHANGES IN MIDDLE EAR CLEFT IN CHRONIC SUPPURATIVE OTITIS MEDIA
}

\author{
Sachiv Garg1, Shikha Palta², Bhim Sen Verma ${ }^{3}$
}

1 Medical Officer, Department of ENT, Civil Hospital, Sunam. Punjab.

${ }^{2}$ Senior Resident, Department of Pharmacology, GMC, Patiala, Punjab.

${ }^{3}$ Associate Professor (Ret.), Department of ENT, GMC, Patiala, Punjab.

\section{BACKGROUND}

ABSTRACT

Chronic suppurative otitis media has been traditionally defined as a chronic inflammation of the middle ear and mastoid, usually associated with perforation of the tympanic membrane and otorrhoea. Understanding the pathology and pathogenesis of chronic suppurative otitis media is important in predicting the management, prognosis and sequelae of the disease.

\section{MATERIALS AND METHODS}

The present study was a cross-sectional study that was conducted to evaluate the clinical, intraoperative and histopathological changes in the middle ear cleft. 50 patients diagnosed with CSOM, who underwent surgery were taken. The mucosa and granulation tissue were removed along with ossicles wherever indicated and sent for histopathological examination.

\section{RESULTS}

Incidence of CSOM is highest in $3^{\text {rd }}$ decade of age with more prevalence in lower socioeconomic group. Females were involved more than males. Unilateral involvement was seen in $64 \%$ cases. Otorrhoea and diminished hearing was a constant feature among all cases followed by earache (26\%), itching (22\%), tinnitus (16\%), vertigo (10\%) and mass in the ear (6\%). On otoscopic examination perforation was seen in 42 cases (84\%), while retraction pockets were seen in 8 cases $(16 \%), 7$ cases had plastere d TM (14\%), tympanosclerosis was also found in 6 cases (12\%), granulations in 2 cases (4\%) and polyp was found in 3 cases (6\%). On pure tone audiometry testing, 44 patients (88\%) had conductive hearing loss and 6 patients (12\%) had mixed hearing loss.

\section{CONCLUSION}

Main conclusion drawn from this study is that on clinical examination 38 cases were found to be of tubotympanic type and 12 cases of atticoantral variety. However, intraoperatively, of the tubotympanic cases, 4 were found to be of unsafe type, which was also proven histologically.

\section{KEYWORDS}

CSOM, Middle Ear Cleft, Clinico-Pathological Changes.

HOW TO CITE THIS ARTICLE: Garg S, Palta S, Verma BS. Clinico-Pathological changes in middle ear cleft in chronic suppurative otitis media. J. Evolution Med. Dent. Sci. 2018;7(11):1391-1395, DOI: 10.14260/jemds/2018/316

\section{BACKGROUND}

World Health Organisation defines CSOM as "otorrhoea through a perforated tympanic membrane present for at least 2 weeks," while others define "chronic" as symptoms persisting for more than 6 weeks. ${ }^{1}$ CSOM is the inflammation of middle ear cleft and mastoid cavity, which presents with recurrent ear discharge or otorrhoea through the tympanic membrane perforation. CSOM is a major cause of acquired hearing impairment, especially in developing countries. It affects both the sex and all age groups. ${ }^{2}$

The diagnosis of CSOM implies permanent abnormality of the pars tensa or flaccid, most likely as a result of earlier acute otitis media, negative middle ear pressure or otitis media with effusion. ${ }^{3}$

CSOM is a serious condition with $65-330$ million sufferers, of whom $60 \%$ have significant hearing loss. ${ }^{2}$ In India, the overall prevalence is 46 and 16 persons per

'Financial or Other Competing Interest': None.

Submission 19-01-2018, Peer Review 21-02-2018,

Acceptance 27-02-2018, Published 12-03-2018.

Corresponding Author:

Sachiv Garg,

Medical Officer,

Department of ENT, Civil Hospital, Sunam, Punjab.

E-mail: sachivgarg9@gmail.com

DOI: $10.14260 /$ jemds $/ 2018 / 316$

\section{(c) $(1) \ominus$}

thousand in rural and urban population respectively.4 Otorrhoea and hearing loss were the major presenting symptoms. Hearing loss was moderate-to-severe in $2 / 3$ and slight in $1 / 3$ of the audiometrically tested ears. ${ }^{5}$ The occurrence of CSOM and its complications have reduced considerably with the use of better antibiotics. However, in the developing countries, these infections still are major challenges with respect to diagnosis and management. The complications of CSOM are classified as intracranial and extracranial (intratemporal) or meningeal and nonmeningeal. 6

\section{Objective}

To study clinico-pathological features in different type of chronic suppurative otitis media for better management of tubotympanic and atticoantral type of CSOM.

\section{Types of CSOM}

\section{Clinically, it is divided into Two Types}

\section{Tubotympanic}

Also called the safe or benign type, it involves anteroinferior part of middle ear cleft and is associated with a central perforation. ${ }^{4}$ Among the two types of chronic suppurative otitis media, tubotympanic variety is the commonest and risk of developing complications are less and the name tubotympanic indicates a disease of eustachian tube and tympanic cavity. ${ }^{7}$ 


\section{Atticoantral}

Also called unsafe or dangerous type. It involves posterosuperior part of the cleft (i.e. attic, antrum and mastoid) and is associated with an attic or a marginal perforation. The disease is often associated with a bone-eroding process such as cholesteatoma, granulations or osteitis. Risk of complications is high in this variety. ${ }^{4}$

\section{MATERIALS AND METHODS}

Sample size taken for Convenience was 50 patients of chronic suppurative otitis media at random without any due consideration for a particular type of chronic suppurative otitis media, particular age or sex group were taken for crosssectional study from Ear, Nose and Throat Department of Government Medical College and Rajindra Hospital, Patiala. Patients underwent surgery when the disease was refractory to standard methods of treatment. All the patients were put up for operation after careful clinical examination and investigation. Surgery was performed. Pathological changes in the middle ear were grossly observed and disease tissue was removed and sent for histopathological examination. Material for histopathological study was consisting of mucous membrane from the middle ear cleft, polyp if present, granulation tissue, cholesteatoma tissue when present, ossicles whenever removed, fistulous tract in the skin if present. The material was preserved in $10 \%$ formalin and sent for histopathological examination. Paraffin sections were made after decalcification of the tissue. Material was stained with haematoxylin and eosin. The sections were examined under high power magnification. Microscopic changes were recorded and correlated with operative and clinical findings.

\section{Statistical Analysis}

$P$ value calculated. $P$ value $<0.05$ was considered significant and $\mathrm{P}$ value $<0.001$ was considered highly significant and calculated by chi-square test.

\section{RESULTS}

Ages ranged from 2 years to 55 years. Highest incidence was found in third decade (34\%) followed by second decade (22\%). Study showed a predominance of females with male and female ratio of $1: 1.27$. The majority of cases of CSOM belonged to lower socioeconomic status comprising (56\%), formed about more than half of cases. Unilateral involvement was seen in $64 \%$ cases, while bilateral involvement was seen in $36 \%$ cases. Left ear was operated in $58 \%$ cases and right ear in $42 \%$. On the basis of history, clinical examination 38 patients $(76 \%)$ were found to have safe type (Tubotympanic) and 12 patients (24\%) were found to have unsafe type of disease (Atticoantral). However, intraoperatively there were $68 \%$ cases of safe type and $32 \%$ cases of unsafe type.

\begin{tabular}{|c|c|c|c|}
\hline Type & Tubotympanic (\%) & Atticoantral (\%) & Total \\
\hline Clinically & $38(76 \%)$ & $12(24 \%)$ & 50 \\
\hline Operatively & $34(68 \%)$ & $16(32 \%)$ & 50 \\
\hline Table 1. Type of CSOM on Clinical and Operative \\
Examination
\end{tabular}

Otorrhoea and diminished hearing was a constant feature among all cases followed by earache (26\%), itching (22\%), tinnitus (16\%), vertigo $(10 \%)$ and mass in the ear $(6 \%)$. Mean duration of discharge was 7.974 years and majority of cases were having mucopurulent ear discharge (58\%). (60\%) were having history of profuse ear discharge, while $(24 \%)$ were having moderate and (16\%) having scanty ear discharge. $(24 \%)$ were having foul smelling discharge. Foul smelling discharge was mainly of musty odour.

On otoscopic examination, perforation was seen in 42 cases (84\%), while retraction pockets were seen in 8 cases (16\%), 7 cases had plastered TM (14\%), tympanosclerosis was also found in 6 cases (12\%), granulations in 2 cases (4\%) and polyp was found in 3 cases (6\%). Retraction pockets either isolated or associated with other findings were commonest in the postero-superior quadrant.

\begin{tabular}{|c|c|c|c|}
\hline Finding & Atticoantral & Tubotympanic & P value \\
\hline Perforation & $4(33.3 \%)$ & $38.0(100 \%)$ & $<0.001(\mathrm{HS})$ \\
\hline Plastered TM & $7(58.3 \%)$ & - & $<0.001(\mathrm{HS})$ \\
\hline $\begin{array}{c}\text { Retraction } \\
\text { Pocket }\end{array}$ & $8(66.6 \%)$ & - & $<0.001(\mathrm{HS})$ \\
\hline Granulations & $2(16.6 \%)$ & - & $\begin{array}{c}\text { Not } \\
\text { Significant }\end{array}$ \\
\hline Polyp & $2(16.6 \%)$ & 1 & $\begin{array}{c}\text { Not } \\
\text { Significant }\end{array}$ \\
\hline \multicolumn{4}{|c|}{ Table 2. Otoscopic Finding in Tubotympanic and } \\
Atticoantral Variants
\end{tabular}

On x-ray of mastoid, $70 \%$ mastoids were sclerosed followed by mixed mastoids (28\%) and well pneumatised mastoids was found in 1 case (2\%). CT scan examination of mastoid and middle ear 7 cases (14\%) showed the presence of cholesteatoma. Scutum was found eroded in 3 cases (6\%). Erosion of lateral attic wall was found in 4 cases (8\%). Ossicular chain was found eroded in 12 cases (24\%). Ossicles were found displaced in 3 cases, but erosion was not present. Facial nerve canal was found eroded in 1 case. In 10 cases (20\%), soft tissue density material was extending from middle ear to mastoid through aditus and aditus was blocked. 35 cases $(70 \%)$ were having sclerotic mastoid. Tegmen was found eroded in two cases. All the 7 cases with underlying cholesteatoma were showing mastoid bone erosion. Bone destruction was a feature of underlying cholesteatoma. On pure tone audiometry testing 44 patients (88\%) had conductive hearing loss and 6 patients $(12 \%)$ had mixed hearing loss, while none of our patients had sensorineural hearing loss. Most of the patients had moderate hearing loss (44\%), while $38 \%$ had mild hearing loss, $14 \%$ had moderately severe hearing loss and $4 \%$ had severe hearing loss. Type or degree of hearing loss had no significant association with safe or unsafe chronic otitis media. Aural swabs were taken under sterile condition and sent for culture and sensitivity. Sample cultured from diseased ear showed monomicrobial growth in $72.7 \%$ cases, while another $16.6 \%$ showed polymicrobial growth. No growth could be obtained in $9.5 \%$ cases. Pseudomonas aeruginosa was the most common prevalent organism (57.1\%), other organism cultured in our study were E. coli $(11.9 \%)$ and citrobacter (4.7\%). Amikacin appears to be the most potent drug. There were 16 cases of atticoantral type and 34 cases of tubotympanic type intraoperatively. Based upon intraoperative findings, patients were reclassified as those with safe or those with unsafe CSOM. Four cases which were clinically classified as safe were found to be unsafe intraoperatively. Of these 4 cases 3 had granulations, while 2 had granulations with cholesteatoma. On surgical 
exploration, hyperplastic mucosa was the commonest pathology in the antrum and middle ear. Granulations in the middle ear were seen in 13 cases. 8 patients had cholesteatoma localised in the middle ear as compared to 2 in the antrum.

\begin{tabular}{|c|c|c|}
\hline Pathology & $\begin{array}{c}\text { Mastoid Antrum } \\
(\%)\end{array}$ & $\begin{array}{l}\text { Middle Ear } \\
(\%)\end{array}$ \\
\hline Hyperplastic & $13(26 \%)$ & $18(36 \%)$ \\
\hline Oedematous & $11(22 \%)$ & $10(20 \%)$ \\
\hline Glue & $4(8 \%)$ & $1(2 \%)$ \\
\hline Granulations & $7(14 \%)$ & $13(26 \%)$ \\
\hline Cholesteatoma & $2(4 \%)$ & $8(16 \%)$ \\
\hline Cholesterol granuloma & $1(2 \%)$ & $1(2 \%)$ \\
\hline Tympanosclerosis & - & $8(16 \%)$ \\
\hline Normal & $12(24 \%)$ & $3(6 \%)$ \\
\hline
\end{tabular}

Incus was the commonest ossicle to be eroded (32\%) followed by stapes suprastructure $(20 \%)$. Malleus was eroded in $16 \%$ cases. Metaplasia of the epithelial lining was of stratified squamous type in $64 \%$ of the cases, while keratinised stratified squamous epithelium was seen in $16 \%$ cases. Cuboidal epithelium was seen in $12 \%$ cases, $6 \%$ had pseudostratified squamous and $2 \%$ had pseudostratified columnar epithelium. Fibrosis was increased in $80 \%$ cases, $64 \%$ amongst these showing minimal increase. Increase in vascularity was seen in $64 \%$ cases. Calcification was seen in $36 \%$, ossification in $32 \%$, while neogland formation was seen in only $2 \%$ cases. Lymphocytes were increased in all the cases, while an increase in plasma cells was seen in $80 \%$ cases. An increase in histiocytes was seen in $60 \%$ cases, giant cells were observed in $10 \%$ cases. Patients were on regular follow-up for a period of 3 months. Out of 50 cases studied, complications were present in 4 patients (8\%). 2 patients were having stitch abscess (4\%). 1 patient was having mastoid abscess $(2 \%)$ and 1 patient had facial nerve palsy. Overall prevalence of complications was $8 \%$.

\section{DISCUSSION}

In the present study, highest incidence of chronic suppurative otitis media was observed in third decade (34\%) followed by second decade (22\%). Total $60 \%$ cases were from $0-30$ years' age group. In a study done by Baig et al[8] (2011), the highest incidence of CSOM was found in the third decade (40.0\%) followed by second decade $(20.0 \%)$ and $68 \%$ cases of CSOM were from 0 - 30 years' age group, which was similar to our present study. Berron[9] (1983) found the incidence of chronic suppurative otitis media to be higher in 20 - 30 years' age group. In our present study out of 50 cases of CSOM, females constituted $56 \%$ and males $44 \%$. Male-to-female ratio being approximately 1: 1.27 . Mansoor et al[10] (2009) reported a female preponderance (52\%) with male: female ratio of 1: 1.08. Memon et al[11] (2008) also showed a female preponderance (55.9\%) with male: female ratio of $1: 1.2$

According to our study majority of the patients belonged to lower socioeconomic status comprising (56\%), 20\% lower middle, $16 \%$ middle and $4 \%$ from upper middle and upper class. In a study done by Baig et al[8] (2011), majority of patients $(69 \%)$ had poor socioeconomic status. Berron[9] (1983) also found that majority of patients were from rural background and poor socioeconomic status. Poor hygiene, malnutrition, overcrowding, lack of awareness, accessibility and specialist contribute to increased prevalence of the disease in lower socioeconomic group.

Left ear was operated in 58\% cases and right ear in $42 \%$. Unilateral involvement was seen in $64 \%$ cases, while both the ear involved in 36\% cases. Memon et al[11] (2008) reported bilateral involvement was seen in $35 \%$ patients, while most of the cases had unilateral presentation (65\%).

In the present study, there were $76 \%$ cases of tubotympanic otitis media and $24 \%$ cases of otitis media of atticoantral type. However, on surgical exploration unsafe otitis media was seen in $32 \%$ cases, while safe otitis media was seen in $68 \%$ cases. Of the 4 cases which were clinically found to be safe, but unsafe intraoperatively 2 had granulations, while another 2 had granulations along with cholesteatoma. Adhikari et al[12] (2009) found 76\% patients had tubotympanic otitis media, while $24 \%$ had atticoantral disease on clinical examination which was similar to our study. Yaor et al[13] (2006) reported 34.2\% patients had cholesteatoma, while $65.8 \%$ had non-cholesteatomatous disease which was comparable to our study. Memon et al[11] (2008) found that safe disease without cholesteatoma was present in $88.5 \%$ cases and unsafe disease with cholesteatoma was present in $11.5 \%$ cases. In other study done by Baig et al[8] (2011), safe disease without cholesteatoma was found in $89.3 \%$ cases and unsafe disease with cholesteatoma was found in $10.6 \%$ cases.

Otorrhoea and deafness was present in all cases at the time of presentation, otalgia in $26 \%$, itching in $22 \%$, vertigo in $10 \%$, tinnitus in $16 \%$ and mass in the ear $6 \%$. In a study done by Varshney et al[14] (2011), ear discharge was present in $100 \%$ cases. In a study done by Memon et al[11] (2008), $86 \%$ ears were discharging at the time of presentation. Alabbasi et al[15] (2010) reported that otorrhoea was the most common finding (100\%). Salman et al[16] (2009) found that otorrhoea was present in all cases (100\%). Garap et al[17] (2001) found otorrhoea remained the most common presentation in all age groups. In the present study primary complaint of hearing loss was present in $100 \%$ cases, which is comparable with the study done by Varshney et al[14] (2011) with $88.67 \%$ cases having complaint of hearing loss. Symptomatology of patients of our present study was in concordance with study of Varshney et al[14] (2010), Alabbasi et al[15] (2010) and Salman et al[16] (2009).

In the present study, majority of cases had history of 1 - 5 years' duration of ear discharge (38\%) and 0 to 1 year $(22 \%)$. 10 cases $(20 \%)$ had discharge for more than 15 years. Twenty percent cases (20\%) were having ear discharge from 6 - 15 years' duration. Duration varied from 5 months to 25 years. In a study by Varshney et al[14] (2010), on safe CSOM patients duration of discharge varied from 6 months to 50 years with 26 patients having duration of discharge ranging from 1 - 5 years. Kasliwal et al[18] (2004) reported $40 \%$ of the patients were symptomatic for less than 5 years of age. Long duration of discharge was associated with increased chances of complications. In the present study, majority of cases (58\%) presented with mucopurulent discharge and 12 cases (24\%) having mucoid ear discharge. Only 6 cases $(12 \%)$ showed purulent discharge. Chowdhary et al[19] (2002) reported aural discharge was mucoid or mucopurulent in majority of the cases $(80 \%)$. Three cases $(6 \%)$ were having blood tinged discharge, which was further supported by 
presence of granulation tissue in the middle ear. Discharge was foul smelling in 12 cases (24\%), which was suggestive of underlying bone destruction and unsafe disease.

Sclerotic mastoid was seen in $70 \%$ cases $28 \%$ had diploic air cells, while well pneumatised air cells were present in $2 \%$ cases. On CT scan examination of mastoid and middle ear, erosion of scutum was found in $6 \%$ cases and erosion of lateral attic wall in $8 \%$ cases. Ossicular erosion was found in $24 \%$ cases. In $20 \%$ cases, soft tissue density material present in middle ear was extending to mastoid through aditus. This is consistent with Gandhi et al[20] (2001) studies, which suggested that majority of the diseased ear had sclerosed mastoid in majority of cases.

$88 \%$ had conductive hearing loss, $12 \%$ had mixed, while none of the patients had sensorineural hearing loss. Most of the patients had moderate ( $41-55 \mathrm{db}$ ) hearing loss $(44 \%)$, while $38 \%$ had mild (26 - $40 \mathrm{db}$ ) hearing loss. $14 \%$ had moderately severe (56 - $70 \mathrm{db}$ ) hearing loss and $4 \%$ had severe $(71-90 \mathrm{db})$ hearing loss. This is consistent with study conducted by Azevedo et al[21] (2007) which suggested that incidence of mixed hearing loss was $13 \%$, conductive hearing loss in $82 \%$; however, incidence of sensorineural hearing loss was $5 \%$ in this study. Nepal et al[22] (2007) in a study on 100 cases with conductive hearing loss found that $45 \%$ had moderate hearing loss, $26 \%$ had mild and the rest had moderately severe conductive hearing loss similar to our study, which was also consistent with our findings. Biswas et al[7] (2010). In audiological assessment of 51 cases with perforation, most (49.01\%) had an air conduction threshold of $>30 \mathrm{db}$, while $35.21 \%$ had threshold of $20-30 \mathrm{db}$.

Sample culture from diseased ear shows monomicrobial growth in $72.7 \%$ cases, while another $16.6 \%$ showed polymicrobial growth. No growth could be obtained in $9.5 \%$ samples. Pseudomonas aeruginosa was the most common organism prevalent $(57.1 \%)$. Apart from pseudomonas, other organism cultured in our study were E. coli $(11.9 \%)$ and Citrobacter (4.7\%). Amikacin appears to be the most potent drug. Poorey et al[23] (2002) found pseudomonas (35\%) was found to be the most common isolate in aural swabs followed by Klebsiella (25\%). Amikacin was found to be the most potent antibiotic followed by ciprofloxacin, which was comparative to our study.

Hyperplastic mucosa was the commonest finding (36\%), oedematous (20\%) and polypoidal mucosa (20\%) was also common. Granulations (26\%) and cholesteatoma (16\%) were more common in the middle ear. Memon et al[11] (2008) saw that cholesteatoma and granulations were present in $11.5 \%$ cases. Comparable to our study an unusual finding in this was the presence of central perforation in 2 cases of unsafe disease which was contrary to the common observation of marginal or attic perforation, retraction pockets associated with unsafe disease. Bhusal et al[24] (2006) also reported similar finding of central perforation in case of unsafe disease. Udaipurwala et al[25] (1994) studies suggested granulations $(63 \%)$ to be more common than cholesteatoma (21\%) in unsafe diseases. Baig et al[8] (2011), cholesteatoma was found in $10.63 \%$ cases. Granulation tissue associated with other pathologies was found to be more common than cholesteatoma. This could be because most of the patients in our study were of lower socioeconomic status, hence underwent inadequate treatment, both topical and systemic causing bone destruction and formation of granulation tissue as a response to osteitis.

Incus was the commonest ossicle to be eroded (32\%) followed by stapes suprastructure (20\%). Malleus (16\%) was the most resistant. Udaipurwala et al[25] (1994), Ossicular damage was seen in $52 \%$ cases of chronic otitis media. No ossicular pathology in $48 \%$ of the cases and involvement of 3 ossicle in $40 \%$ cases. Incus erosion was observed in $41 \%$ cases, stapes in $21 \%$. However, malleus erosion was slightly higher than our study. Dornelles et al[26] (2007), Incus was the most frequently affected and with erosion of long process in $47.6 \%$ followed by stapes suprastructure erosion in $32.3 \%$ malleus was least eroded.

Middle ear cleft epithelium of stratified squamous type was the commonest (64\%) followed by keratinised stratified squamous in $16 \%$ cases. Inflammation of middle ear submucosa was seen in all cases, while increase in fibrosis was seen in $80 \%$. Neogland formation was seen in only $2 \%$ cases. An increase in lymphocytes was seen in all cases, an increase in plasma cells was also common (90\%). Histiocytes were increased in $40 \%$ cases, while giant cells were increased only in $10 \%$ cases.

Bhattacharya[27] (2002) found incidence of stratified squamous epithelium with or without keratinisation was highest (82\%) followed by ciliated columnar epithelium, which was comparable to our study. Changes in submucosa was inflammatory cell, infiltration mainly by lymphocytes (98\%) which was also consistent with our findings. Mastoid abscess was found in $2 \%$ cases followed by facial nerve palsy in $2 \%$ cases. In a study done by Memon et al[11] (2008) mastoid abscess was present in $1.02 \%$ cases, exposed facial nerve in $1.53 \%$ cases. Prevalence of complications in this study was $6.4 \%$, while in our study prevalence was $8 \%$. In a study done by Baig et al[8] (2011) mastoid abscess was present in $1.17 \%$ cases, facial nerve palsy in $1.76 \%$ cases. Prevalence of complications in this study was $7 \%$, while in our study, prevalence is $8 \%$. So the prevalence of these complications in our study was comparable. Incidence of complications has reduced drastically following the advent of antibiotics and advanced surgical care.

\section{CONCLUSION}

Main conclusion drawn from this study is that incidence of CSOM is highest in $3^{\text {rd }}$ decade of age with more prevalence in lower socioeconomic group. Females are involved more than males. Tubotympanic variety is more common than atticoantral type. Otorrhoea and decreased hearing are universal findings. Perforations are more common in tubotympanic type, while retraction pockets involving postero-superior quadrant are more common in atticoantral variety. Radiologically, mastoid is sclerosed in most of the cases with conductive type of hearing loss. Four cases which were clinically classified as tubotympanic type were found to be atticoantral type intraoperatively. Hyperplastic mucosa is the commonest finding in the mastoid antrum and middle ear with incus being the commonest ossicle eroded followed by stapes suprastructure and malleus. Improvement of socioeconomic status of people, early recognition and treatment of chronic suppurative otitis media can reduce the number of cases and complications of the disease. 


\section{REFERENCES}

[1] Verhoeff M, van der Veen EL, Rovers MM, et al. Chronic suppurative otitis media: a review. Int J Pediatr Otorhinolaryngol 2006;70(1):1-12.

[2] Jahn AF. Chronic otitis media: diagnosis and treatment. Med Clin North Am 1991;75(6):1277-91.

[3] Browing GG. Chronic otitis media. In: Otorhinolaryngology head and neck surgery. $7^{\text {th }}$ edn. Scott Brown's, 2008;237(3):3396.

[4] ENT World diseases of the ear, nose and throat. Chronic suppurative otitis media. Tuesday, December 28, 2010.

[5] Matanda RN, Muyunga KC, Sabue MJ, et al. Chronic suppurative otitis media and related complications at University clinic of Kinshasa. B-ENT 2005;1(2):57-62.

[6] Dubey SP, Larawin V. Complications of chronic suppurative otitis media and their management. Laryngoscope 2007;117(2):264-7.

[7] Biswas SS, Hossain MA, Alam MM, et al. Hearing evaluation after myringoplasty. Bangladesh J Otorhinolaryngol 2010;16(1):23-8.

[8] Baig MM, Ajmal M, Saeed I, et al. Prevalence of cholesteatoma and its complications in patients of chronic suppurative otitis media. JRMC 2011;15(1):16-7.

[9] Berzon DB. Ear disease in a group general practice. A review of world communities. J Laryngol Otol 1983;97(9):817-24.

[10] Mansoor T, Musani MA, Khalid G, et al. Pseudomonas aeruginosa in chronic suppurative otitis media: sensitivity spectrum against various antibiotics in Karachi. J Ayub Med Coll Abbottabad 2009;21(2):1203.

[11] Memon MA, Matiullah S, Ahmed Z, et al. Frequancy of unsafe chronic suppurative otitis in patients with discharging ear. JLUMHS 2008:102-5.

[12] Adhikari P, Joshi S, Baral D, et al. Chronic suppurative otitis media in urban private school children of Nepal. Braz J Otolaryngol 2009;75(5):669-72.

[13] Yaor MA, El-Kholy, Jafari B. Surgical management of chronic suppurative otitis media. A three year experience. Annals of African Medicine 2006;5:24-7.

[14] Varshney S, Nangia A, Bist SS, et al. Ossicular chain status in chronic suppurative otitis media in adults. Indian J Otolaryngolol Head Neck Surg 2010;62(4):421-6.
[15] Alabbasi AM, Alsaimary IE, Najum JM. Prevalence and patterns of chronic suppurative otitis media and hearing impairment in Basrah city. J Med Med Sci 2010;1(4):129-33.

[16] Salman AA, Azhar H, Muhammad EK, et al. Analytical study of ossicular chain in middle ear cholesteatoma. Annals 2009;15(3):134-7.

[17] Garap JP, Dubey SP. Canal-down mastoidectomy: experience in 81 cases. Otol Neurotol 2001;22(4):4516.

[18] Kasliwal N, Joshi S, Pareek SM. Determinants of sensorineural hearing loss in chronic middle-ear disease. Indian J Otolaryngol Head Neck Surg 2004;56(4):269-73.

[19] Chowdhary MA, Alauddin M. Comparative study between tubotympanic and atticiantral types of chronic suppurative otitis media. Bangladesh Med Res Counc Bull 2002;28(1):36-44.

[20] Gandhi BS, Aggarwal AK. Clinical profile of patients with complications following otitis media. Indian J Otolaryngol Head Neck Surg 2001;53(1):11-3.

[21] De Azevedo AF, Pinto DC, de Souza NJ, et al. Sensorineural hearing loss in chronic suppurative otitis media with and without cholesteatoma. Braz J Otorrinolaringol 2007;73(5):671-4.

[22] Nepal A, Bhandary S, Mishra SC, et al. The morphology of central tympanic membrane perforations. Nepal Med Coll J 2007;9(4):239-44.

[23] Poorey VK, Lyer A. Study of bacterial flora in csom and its clinical significance. Indian J Otolaryngol Head Neck Surg 2002;54(2):91-5.

[24] Bhusal CL, Guragain RP, Shrivastav RP. Size of tympanic membrane perforation and hearing loss. JNMA J Nepal Med Assoc 2006;45(161):167-72.

[25] Udaipurwala IH, Iqbal K, Saqulain G, et al. Pathological profile in chronic suppurative otitis media--the regional experience. J Pak Med Assoc 1994;44(10):235-7.

[26] Dornelles C, Rosito LP, Meurer L, et al. Histology findings correlation between the ossicular chain in the transoperative and cholesteatomas. Braz J Otorrhinolaringol 2007;73(6):738-43.

[27] Bhattacharya M. Histopathological study of middle ear mucosa in chronic otitis media. Indian Journal of Otology 2002;9:16-21. 